\title{
Study on the Effect of Belt Velocity on the Dust Emission for Coal Transit Spot in Fossil Power Plants
}

\author{
Musong $\mathrm{Lin}^{1}$, Yuchun $\mathrm{Li}^{2, *}$, Zhaojin $\mathrm{Xu}^{2}$,Lei $\mathrm{Ma}^{2}$ and Mengxin $\mathrm{Mi}^{2}$ \\ ${ }^{1}$ Electric Power Research Institute of Guangdong Power Grid Co. Ltd., Guangzhou 510080, China \\ ${ }^{2}$ School of Chemistry \&Biological Engineering, Changsha University of Science \& Technology, Changsha 410114, China \\ ${ }^{*}$ Corresponding author
}

\begin{abstract}
By dynamic simulating bench for coal transit spot in fossil power plants, dust emission was studied and characterized with different levels of belt velocity in this article. There is a very strong negative correlation between upper concentration and lower concentration of coal dust with different belt velocity. The Spearman correlation coefficient is $\mathbf{- 0 . 8 9 2 9}$; the significance probability is 0.0068 .
\end{abstract}

Keywords-dust emission; dynamic coal flow; characterization analysis; correlation coefficient

\section{INTRODUCTION}

In coal-consuming power plants, coal fuel becomes the most important source of atmospheric pollutants, such as 'acid rain' or coal dust ${ }^{[1,2]}$. A series of emission studies has been conducted and indicated that the power sector accounts for $45 \%$ of national anthropogenic emission of $\mathrm{SO}_{2}, 28 \%$ of $\mathrm{NO}_{\mathrm{x}}$ and $9 \%$ of particulate matter ${ }^{[3-5]}$. However, transit spot of coal flow in a fossil power plant is a very contaminative location for regional working environment. Because of large quantities of coal dust from dynamic coal flow, it was necessary to study dynamic coal flow and evaluate coal dust emission of coal flow transit spot.

The paper gave a systematic study on dust emission released from dynamic coal flow transit spot. By analyzing the emission of dust with different velocity and coal particle size, evaluation model of the emission can be discussed and be used for guiding the site assessment in fossil power plants.

\section{EXPERIMENTAL METHODS}

The scheme of simulating bench for coal transit spot was showed in Figure 1. Through control console, high-level and low-level belt can acquire variant velocity for simulating transit spot conditions.

With the buffer role of gathering sills, coal flow drops to low-level belt. Coal dust can be generated due to the impact interaction between coal particle and low-level belts. The general velocity of belts in a fossil power plant is ranged from $1.5 \sim 3.5 \mathrm{~m} / \mathrm{s}$. Here the velocity selection was followed as Table 1 , the size distributions of tested coal were also listed after grinding treatment.

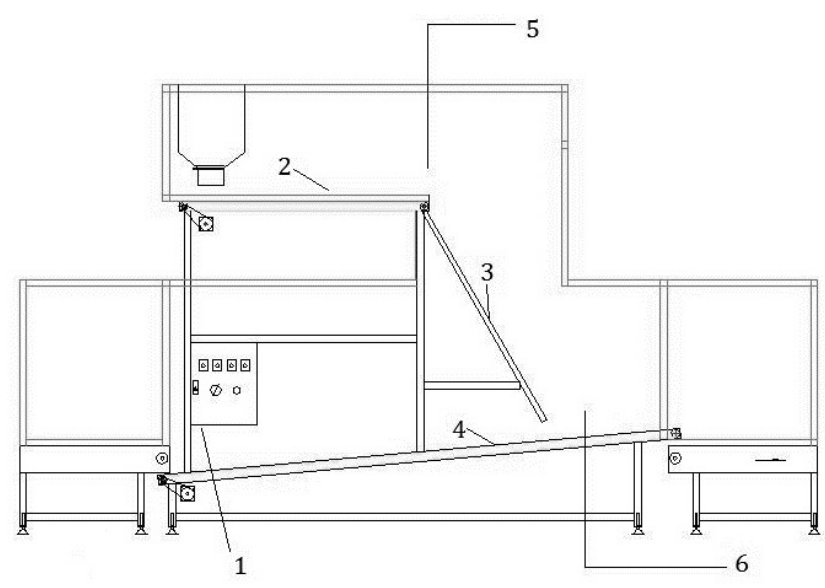

1. Control console 2. High-level belt 3. Gathering sills 4. Low-level belt 5. Upper dust monitors location 6. Lower dust monitors location FIGURE I. SIMULATING TEST BENCH OF TRANSIT SPOT IN FOSSIL POWER PLANT

TABLE I. EXPERIMENTAL CONDITION FOR SIMULATING BENCH

\begin{tabular}{|l|l|l|l|l|l|l|l|}
\hline $\begin{array}{l}\text { Level } \\
\text { grade }\end{array}$ & 1 & 2 & 3 & 4 & 5 & 6 & 7 \\
\hline $\begin{array}{l}\text { Velocity, } \\
\mathrm{m} / \mathrm{s}\end{array}$ & 1.0 & 1.5 & 2.0 & 2.5 & 3.0 & 3.5 & 4.0 \\
\hline $\begin{array}{l}\text { Aver. size } \\
\text { of coal, } \\
\text { meshes }\end{array}$ & 20 & 40 & 60 & 80 & 100 & 120 & $>120$ \\
\hline
\end{tabular}

Figure 2 showed the actual photos of simulating bench for dynamic coal flow in fossil power plants. Figure 2(a) is the overall photo of simulating bench, and the height between high-level belts and low-level belts is 1.5 meters. Figure 2(b) is motor inverter of simulating bench. Origin 9.0 and Matlab 2013b were employed for data analysis and modeling. 


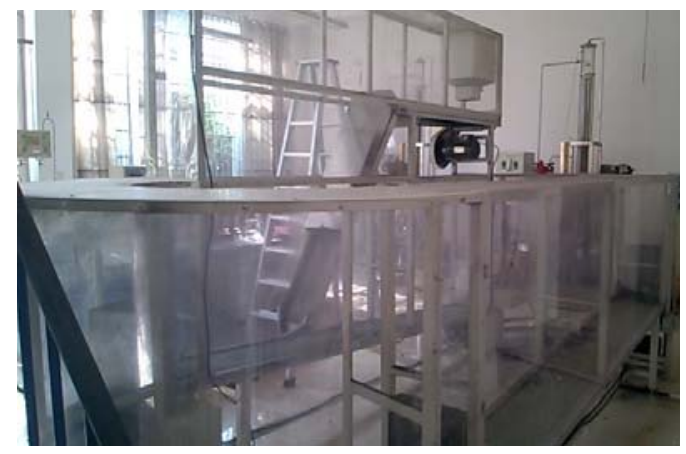

(a) Overall photo of simulating bench

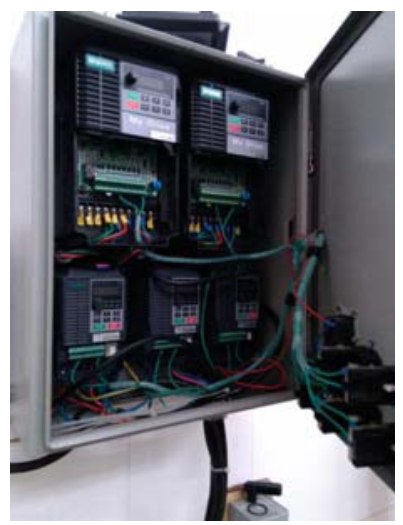

(b) Motor inverter of simulating bench

FIGURE II. FIELD PHOTOS OF SIMULATING BENCH FOR DYNAMIC COAL FLOW SYSTEM

\section{RESULTS}

\section{A. Measurement Results of Concentrations of Coal Dust}

Figure 3 showed the concentrations of coal dust for highlevel and low-level location with different belt velocity. The unit of dust concentration is $\mathrm{mg} / \mathrm{m}^{3}$. Because there were three parallel experiments for each test of one velocity, the displayed values were all average value for 3 parallel experiments.

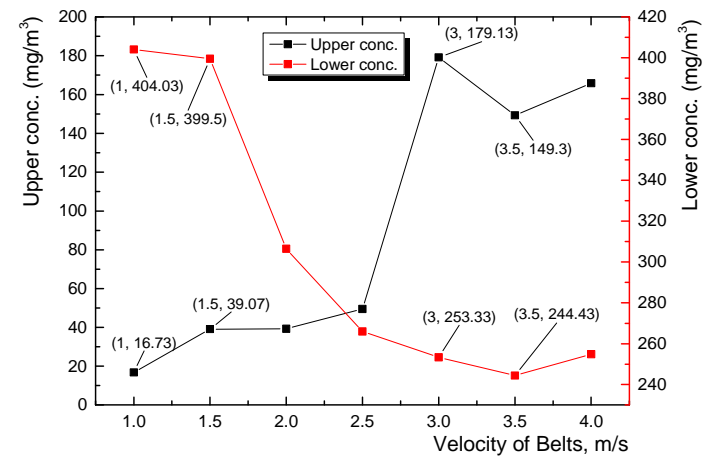

FIGURE III. CONCENTRATIONS COMPARISON BETWEEN HIGHLEVEL AND LOW-LEVEL COAL DUST WITH DIFFERENT BELT VELOCITY.
B. Mass loss and Diffusion rate of Each Experiment with Different Belt Velocity

Table 2 showed the mass loss of each experiment with different belts velocity. The diffusion rates from coal sample to outside atmosphere were also listed. Because there were 3 parallel experiments for each test of one velocity, the displayed values were the average value for 3 parallel experiments.

TABLE II. MASS LOSS FOR SIMULATING EXPERIMENT WITH DIFFERENT VELOCITY.

\begin{tabular}{|c|c|c|c|c|}
\hline $\begin{array}{l}\text { Velocity, } \\
\mathrm{m} / \mathrm{s}\end{array}$ & Mass-0, g & Mass-1, g & mass loss, g & $\begin{array}{l}\text { diffusion } \\
\text { rate, \% }\end{array}$ \\
\hline 1.0 & 929.15 & 856.13 & 73.02 & 7.86 \\
\hline 1.5 & 929.13 & 841.17 & 87.96 & 9.47 \\
\hline 2.0 & 929.11 & 814.52 & 114.59 & 12.33 \\
\hline 2.5 & 929.09 & 804.64 & 124.45 & 13.39 \\
\hline 3.0 & 929.12 & 810.54 & 118.58 & 12.76 \\
\hline 3.5 & 929.06 & 779.76 & 149.30 & 16.07 \\
\hline 4.0 & 929.09 & 737.35 & 191.74 & 20.64 \\
\hline
\end{tabular}

Table 3 showed the mass loss for different particle size with $1 \mathrm{~m} / \mathrm{s}$ belt velocity. The diffusion rates from each kind of coal particle to outside atmosphere were also listed. There were 3 parallel experiments for $1 \mathrm{~m} / \mathrm{s}$ belt velocity. The data in Table 3 were only from one experiment.

TABLE III. MASS LOSS FOR SIMULATING EXPERIMENT WITH DIFFERENT PARTICLE SIZE

\begin{tabular}{|c|c|c|c|c|}
\hline $\begin{array}{l}\text { Size, } \\
\text { meshes }\end{array}$ & Mass-0, g & Mass-1, g & mass loss, g & $\begin{array}{l}\text { diffusion } \\
\text { rate, \% }\end{array}$ \\
\hline 20 & 290.04 & 265.11 & 24.93 & 8.60 \\
\hline 40 & 237.01 & 235 & 2.01 & 0.85 \\
\hline 60 & 106.02 & 105.71 & 0.31 & 0.29 \\
\hline 80 & 103.02 & 100.98 & 2.04 & 1.98 \\
\hline 100 & 71 & 65.64 & 5.36 & 7.55 \\
\hline 120 & 65.05 & 60.13 & 4.92 & 7.56 \\
\hline$>120$ & 57.04 & 21.82 & 35.22 & 61.75 \\
\hline
\end{tabular}

\section{ANALYSIS AND DISCUSSION}

\section{A. Analysis of Coal Dust Concentration of High-Level \&} Lower-Level Belt

Figure 4 showed the statistical graph of dust concentration according to Figure 3 . It can be indicated that dust concentration in lower-belt was ranged from $250 \sim 410 \mathrm{mg} / \mathrm{m}^{3}$. The distribution of lower-belt concentration approximately conformed to normality distribution. However, the dust concentration in high-belt was ranged from $10 \sim 200 \mathrm{mg} / \mathrm{m}^{3}$. The distribution of high-belt concentration roughly conformed to lognormal distribution. 

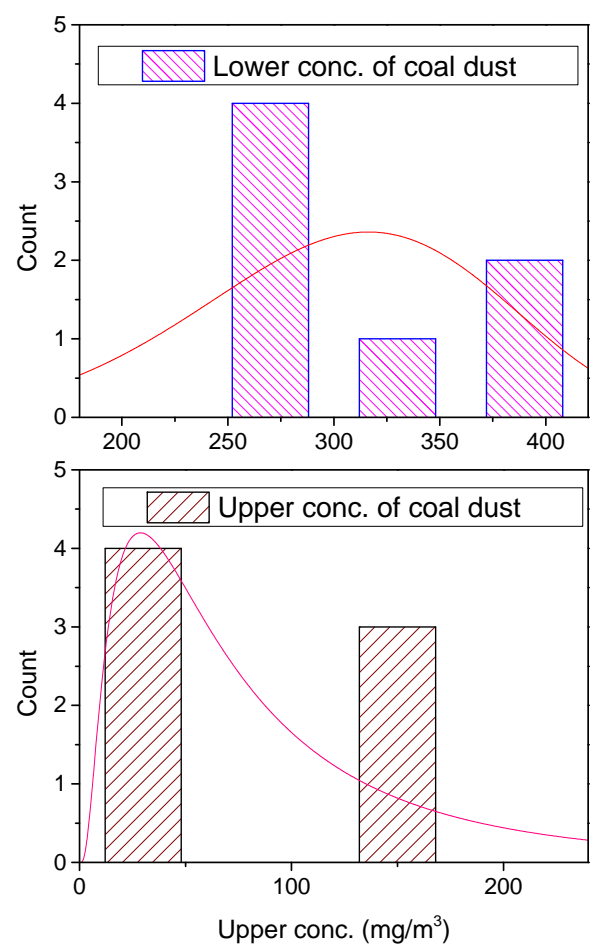

FIGURE IV. STATISTICAL GRAPH OF DUST CONCENTRATION FOR HIGH-LEVEL AND LOWER-LEVEL BELT

Because of distribution difference for two data columns, correlation analysis was performed according to Spearman correlation coefficient. By analysis of Origin 9.0, the Spearman correlation coefficient between the upper concentration and the lower concentration is -0.8929 . The significance probability is 0.0068. It displayed that there is a very strong negative correlation between two columns of concentration data with different belt velocity.

\section{B. Analysis of Mass Loss for Simulated Process of Dynamic Coal Flow}

Figure 5 showed XYY plot of mass loss and diffusion rate of the test sample with different particle size. The $(x, y)$ values of some points were also shown in this figure, and the value of red color is corresponding to the right $\mathrm{Y}$ axis for indicating diffusion rate (unit \%). It can be indicated that mass loss increases with increase of meshes (i.e. decrease of particle size) However, for 20 meshes particles, there are high mass loss and diffusion rate. The reason for this phenomenon lies in that big coal particle may be thrown away from coal belts during the transportation process of coal flow. This part of loss for big particle cannot form coal dust, but debris, another kind of pollution.

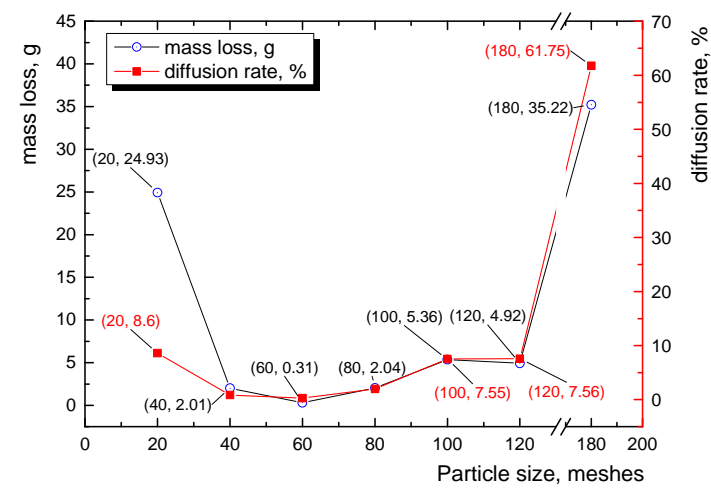

FIGURE V. XYY PLOT OF MASS LOSS AND DIFFUSION RATE OF THE TEST SAMPLE WITH DIFFERENT PARTICLE SIZE

C. Analysis of Correlation between Dust Concentration and Mass Loss

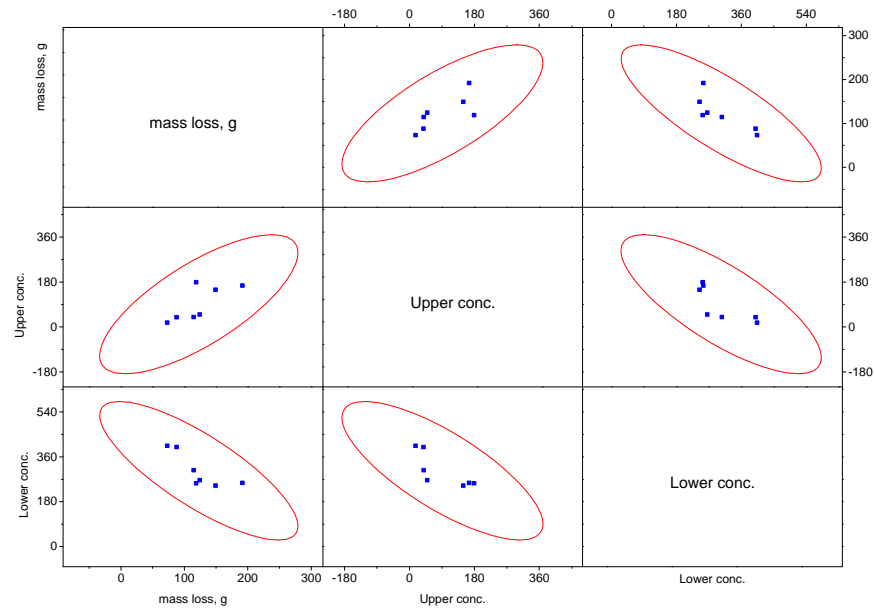

FIGURE VI. SCATTER MATRIX PLOT AMONG MASS LOSS, UPPER AND LOWER DUST CONCENTRATION

By analysis of Origin 9.0, the Spearman correlation coefficient between mass loss and lower dust concentration is 0.8214 . The significance probability is 0.0235 . It displayed that there is a very strong negative correlation between two columns of data with different belt velocity. As the same way, the Spearman correlation coefficient between mass loss and upper dust concentration is 0.7857. The significance probability is 0.0362 . It displayed that there is strong positive correlation between two columns of data with different belt velocity. Figure 6 showed the scatter matrix plot among three columns of data.

\section{CONCLUSION}

Depending on discussion and analysis of dynamic simulating bench of coal transit spot in fossil power plants, there is a very strong negative correlation between upper concentration and lower concentration of coal dust with different belt velocity. The Spearman correlation coefficient is - 
0.8929; the significance probability is 0.0068 . Mass loss of coal dust increases with increase of meshes or the decrease of particle size. The Spearman correlation coefficient between mass loss and lower dust concentration is -0.8214. The Spearman correlation coefficient between mass loss and upper dust concentration is 0.7857 .

\section{ACKNOWLEDGMENT}

The project was sponsored by the Electric Power Research Institute of Guangdong Power Grid Corporation; The authors are grateful to all reviewers of the manuscript for their encouraging comments.

\section{REFERENCES}

[1] A.D. Ferreira, P.A.Vaz. Wind tunnel study of coal dust release from train wagons. J. Wind Eng. Ind. Aerodyn. 92 (2004) 565-577

[2] A.D. Ferreira, D.X.Viegas, A.C.M. Sousa. Full-scale measurements for evaluation of coal dust release from train wagons with two different shelter covers. J. Wind Eng. Ind. Aerodyn. 91(2003)1271-1283

[3] Yu Zhao, Shuxiao Wang,Chris P. Nielsen et al. Establishment of a database of emission factors for atmospheric pollutants from Chinese coal-fired power plants.44 (2010) 1515-1523

[4] Daming Zhang. Study on regularity of coal dust transport and dust treatment technologies in coal conveyor roadway. Ph.D Thesis,Liaoning Technical University, 2010.72-73.

[5] E.M. Fitzpatrick, Bartle, K.D.1; Kubacki, M.L. et al. The mechanism of the formation of soot and other pollutants during the co-firing of coal and pine wood in a fixed bed combustor. Fuel, 88 (2009) 2409-2417. 